\title{
The Impact Of Entry And Competition On Airline Departure Frequency
}

\author{
Wilfred S. Manuela Jr., Ateneo de Manila University, Philippines
}

\begin{abstract}
This paper examines how entry and competition impact departure frequency using data from 1990-2009 on a number of routes served by at least two airlines. The estimated frequency equation indicates that an additional airline at the route level results in a slight decrease in the number of departures despite a substantial increase in passenger traffic since the industry was liberalized in 1995. The results suggest that domestic airlines have shifted to relatively larger aircraft and operate them at higher load factors. The use of larger aircraft operated at higher load factors may indicate their inability to secure additional landing slots, suggesting that investments in air transport infrastructure have not kept pace with demand. Fewer departures indicate that the waiting time between flights has increased, reducing the probability of matching the passengers' preferred departure times with scheduled flights. The longer waiting time between flights and more congestion inside the aircraft due to higher load factors suggest that the service quality of air transport has deteriorated in the post-regulation period.
\end{abstract}

Keywords: airline departure frequency; airline service quality

\section{INTRODUCTION}

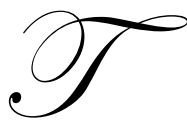

he airline literature defines the quality of airline service in terms of the number of flights, load factor, and aircraft size or technology supplied at the route level (Jorge-Calderon, 1997). More frequent departures tend to reduce waiting time, which enhances airline service quality, and the degree to which flights or passenger seats are matched with the continuous demand for airline service contributes to the convenience of a scheduled transportation system (Douglas and Miller III, 1974). This paper seeks to contribute to the literature on the quality of service of air transport following deregulation and liberalization by examining the impact of entry and competition on departure frequency using a number of domestic routes in the Philippines.

The paper is organized as follows. A brief literature review follows the introduction and then the discussion of the econometric model follows. The fourth section discusses the sample data and methodology while the fifth section presents the estimation results and analysis. The last section concludes and presents some policy implications of the findings on the Philippine domestic airline industry.

\section{DEREGULATION, LIBERALIZATION, AND AIRLINE SERVICE QUALITY}

The impact of deregulation and liberalization on airline service quality is mixed. The service dimension of airline operations in the United States (US) has improved as competition intensified, if the number of departures is considered as an indicator of airline service quality, since the government deregulated the industry in 1978 (Bailey, 1992). In the years following deregulation airline service quality improved in small towns and rural communities due to an increase of between $35 \%$ and $40 \%$ in the number of flights while service quality in high density markets suffered due to increased congestion in airports, departure delays, and passenger discomfort due to higher load factors and narrower seats offered by discount airlines (Kahn, 1993). Notwithstanding the inconveniences experienced by passengers in a liberalized industry, domestic passengers "have more convenient travel options with greater flight frequency and more nonstop flights, resulting in better travel coordination and higher customer satisfaction" (Smith Jr. and Cox, 2008). 
Accessibility, the availability of nonstop service at the route revel, in North Atlantic countries with liberal bilateral agreements increased 38\% between 1969 and 1989, suggesting an improved airline service quality since passengers have more direct flights to choose from (Maillebiau and Hansen, 1995). Moreover, airline departure frequency on fully liberalized intra-European routes is 36\% higher between 1988 and 1992 compared with routes that are not fully liberalized, indicating an improved airline service quality (Rietveld et al., 2002).

\section{ECONOMETRIC MODEL}

The Philippines had a single-airline domestic industry served by the Philippine Airlines (PAL) until 1994. The following year, the government liberalized the airline industry under Executive Order (EO) 219, allowing airlines to enter into and exit from specific routes or the industry. The provisions of EO 219 indicate that only routes with at least two airlines are liberalized and that single-airline routes remain regulated to prevent the airline serving these routes from monopolistic behavior. Airline liberalization as well as entry and competition occurred in the same year, which means that the variable representing the number of airlines operating at the route level captures the impact of liberalization on departure frequency because a change in the number of airlines serving a route indicates that the industry has been liberalized. Moreover, the number of airlines also captures the degree of competition at the route level since more airlines serving a route indicate a more competitive market (Besanko et al., 2007; Borenstein, 1992; Bresnahan and Reiss, 1991).

Graham et al. (1983) use aggregate route-specific data in their study of the US domestic airline industry while Dresner and Tretheway (1992) explore the adequacy of using route-specific variables and conclude that individual airline behavior averages out at the route level, justifying the use of route-specific data. Since the data set in this paper does not allow for testing the symmetric airline behavior assumption all equations are specified using route-specific variables, analyzing aggregate or average market behavior (Dresner and Tretheway; Rietveld et al., 2002).

The econometric model in this study uses some of the variables in the econometric model developed by Manuela Jr. (2007) based on previous work on air transport (Dresner and Tretheway, 1992; Graham et al., 1983; Jorge-Calderon, 1997; Maillebiau and Hansen, 1995) and consists of two equations due to the endogeneity of the passenger variable in the frequency equation. The two equations are estimated simultaneously to obtain unbiased and consistent estimators (Green, 1997 and Intriligator, 1996) and all variables are expressed in natural logarithms so that the coefficients can be interpreted as elasticities (Dresner and Tretheway, 1992; Maillebiau and Hansen, 1995).

\section{Frequency Equation}

$\ln F R E Q(i j)=\beta_{0}+\beta_{1} \ln A \operatorname{IRL}(i j)+\beta_{2} \ln P A S S(i j)+\beta_{3} \ln L O A D(i j)+\beta_{4} A F C(i j)+\varepsilon(1, i j)$

where for each route $i$ and year $j$,

$\begin{array}{lll}\text { FREQ } & = & \text { number of roundtrip flights } \\ \text { AIRL } & & \text { number of airlines } \\ \text { PASS }= & \text { number of enplaned passengers } \\ \text { LOAD }= & \text { load factor (number of passengers divided by number of passenger seats) } \\ \text { AFC }= & \begin{array}{l}\text { dummy variable representing the lagged effect of the 1997 Asian financial crisis, } \\ \text { which assumes a value of "1" from 1998-1999 and "0" otherwise }\end{array} \\ \varepsilon \quad= & \text { error term }\end{array}$

Decisions on departure frequency are relatively easier and cheaper in accommodating additional demand compared with using larger aircraft since the former requires the use of the airlines' existing aircraft while the latter requires the lease or purchase of larger aircraft (Graham et al., 1983; Rietveld et al., 2002). Philippine carriers' respond to a seasonal increase in demand, which usually happens during long holidays around Christmas, New Year, Easter, and school recess between semesters, by adding more flights. While increasing the number of departures is 
the preferred response of most airlines to accommodate additional demand, decisions on departure frequency, however, are limited by the number of available landing slots in airports at both ends of the city-pair.

The number of roundtrip flights (FREQ) should increase with the number of airlines (AIRL) since more airlines serving a route usually result in more departures as competition intensifies (Bailey, 1992; Graham et al., 1983; Kahn, 1993). If airlines entering a route use larger aircraft than what the incumbent airlines use or if the incumbent airlines shift to larger aircraft following entry of other airlines, however, FREQ may decrease as AIRL increases. While most airlines respond to seasonal increases in demand by adding flights or increasing load factors, airlines switch to or use larger aircraft on routes that experience a more permanent increase in passenger traffic (Graham et al.; Rietveld et al., 2002). Therefore, FREQ should increase with the number of passengers (PASS), should decrease as load factors increase since fuller flights require fewer departures holding demand constant, and should decrease if airlines switch to larger aircraft in addition to increasing load factors. The Asian financial crisis should impact FREQ negatively due to slower economic activity.

\section{Demand Equation}

$\ln \operatorname{PASS}(i j)=\beta_{0}+\beta_{1} \ln F R E Q(i j)+\beta_{2} \ln L O A D(i j)+\beta_{3} \ln \operatorname{DIST}(i j)+\varepsilon(1, i j)$

where for each route $i$ and year $j$,

DIST $=$ roundtrip distance between airports

The other variables are as defined in the frequency equation.

The number of passengers (PASS) should increase with the number of departures (FREQ) since more frequent departures increase the probability of matching the preferred departure times of passengers (Douglas and Miller III, 1974). Passenger traffic should increase with load factor (LOAD) since fuller flights result in more passengers and should also increase with stage-length (DIST) since the time-competitiveness of air travel predominates in longer routes (Jorge-Calderon, 1997).

\section{DATA AND METHODOLOGY}

Airline-related data and information for the period 1990-2009 come from the airlines' reports and communications submitted to the Civil Aeronautics Board (CAB) while data on socioeconomic variables come from the various editions of the Philippine Statistical Yearbook published by the National Statistical Coordination Board. The frequency variable at the route level is estimated by dividing the total number of passenger seats by the average aircraft size, measured as the number of seats available per two-way flight, because the flight frequency tables provided by the airlines to $\mathrm{CAB}$ are not updated frequently enough to reflect flight cancelations due to weather conditions and additional flights as demand conditions improve.

The sample consists of 18 domestic routes served by at least two airlines with more than 100,000 passengers in 2009. The country's largest airline markets, Manila-Cebu and Manila-Davao, had at least two airlines since the government liberalized the industry in 1995. Ten sample routes attracted entry in 1996, two more routes had at least two airlines by 1997, and the four remaining sample routes attracted entry after 1997. Five sample routes reverted to single-airline markets following the 1997 Asian financial crisis and the 2001 terror attacks in the US but all were served by at least two airlines since 2007.

This paper uses the generalized method of moments (GMM) with robust standard errors based on the Newey-West covariance estimator to estimate the system of equations due to the observed heteroskedasticity and autocorrelation in the balanced panel data (Baltagi, 2001; Verbeek, 2000; Wooldridge, 2002) and the fixed effects model (Johnston and DiNardo, 1997) to control for the unobserved heterogeneity between years and city-pairs (Manuela Jr., 2007; Rietveld et al., 2002). 


\section{ESTIMATION RESULTS AND ANALYSIS}

Table 1 presents the estimation results of the frequency equation. The instruments used in the estimation of the system of equations are AFC, AIRL, DIST, FREQ, PASS, the average fare at the route level, and the average of the provincial populations of end-point cities. All variables are highly significant and behave as expected, except AIRL.

Table 1: Estimation Results of the Frequency Equation

\begin{tabular}{|c|c|c|c|c|c|}
\hline Variable & Coefficient & Robust Standard Error & t-Statistic & \multicolumn{2}{|c|}{ Probability } \\
\hline Constant & -5.2868 & 0.3255 & -16.2439 & 0.0000 & $* * *$ \\
\hline AIRL & -0.1704 & 0.0299 & -5.6908 & 0.0000 & $* * *$ \\
\hline PASS & 0.9131 & 0.0240 & 37.9852 & 0.0000 & $* * *$ \\
\hline LOAD & -3.3510 & 0.5034 & -6.6562 & 0.0000 & $* * *$ \\
\hline \multirow[t]{4}{*}{$\mathrm{AFC}$} & -0.0687 & 0.0246 & -2.7943 & 0.0053 & $* * *$ \\
\hline & & & Adjusted $\mathrm{R}^{2}$ & 0.8743 & \\
\hline & & & ded observations & 360 & \\
\hline & & & tem observations & 720 & \\
\hline
\end{tabular}

*** Significant at the $1 \%$ level (highly significant)

The sign and magnitude of the variable representing the number of airlines (AIRL) indicate that an additional airline serving a route results in slightly fewer departures, which may be counterintuitive since entry and competition should result in more flights as airlines compete for passengers by scheduling flights that approximate the preferred departure times of passengers (Douglas and Miller III, 1974). There are a number of ways to explain this result. First, Philippine carriers have shifted from smaller aircraft such as Fokker 50 and YS-11 to relatively larger aircraft such as A319/320 and B737 in the last 10 years. The shift to relatively larger aircraft may be a consequence of the airlines' inability to add more departures in slot-constrained airports as demand increases. Second, routes with fewer airline operators that use smaller aircraft such as DHC-7, Do 328, L-410, and MA60 have more flights compared with routes with more airline operators that use relatively larger aircraft such as A319/320 and B737. Third, when PAL, Cebu Pacific Air, and Air Phil Express, which use relatively larger aircraft, enter the routes dominated by South East Asian Airlines and Zest Airways, which use smaller aircraft, the resulting number of departures may decrease since passengers tend to prefer airlines that use larger aircraft because of the perception that larger aircraft are safer and more comfortable (Jorge-Calderon, 1997). Since passengers prefer larger aircraft airlines that still use smaller aircraft may lose passengers to airlines that have shifted to and use larger aircraft, reducing the total number of flights offered by airlines, both incumbents and new entrants, on a particular route. Fourth, the use of larger aircraft operated at higher load factors also contributes to the overall reduction in the number of departures as competition intensifies. Fifth, airlines operated at lower load factors in the years following liberalization; as competition intensified airlines accommodated the additional demand by increasing load factors and reducing capacity in the form of fewer departures in order to increase profits or reduce losses. The higher load factors observed in recent years suggest that Philippine carriers have reduced capacity by offering fewer flights in order to increase average load factors and improve profitability. This trend has been observed in the US domestic airline industry as airlines scramble to return to profitability after years of huge losses that forced a number of airlines into Chapter 11 bankruptcy. The lagged effect of the 1997 Asian financial crisis, the terror attacks in the US in 2001, the severe acute respiratory syndrome pandemic and the avian flu scare, the most recent financial crisis, and the rising cost of fuel all contribute to the financial woes of airlines worldwide forcing most airlines, including Philippine carriers, to reduce capacity in order to improve profitability or at least stem operating losses in an increasingly competitive and risky environment.

The estimation results indicate that passenger traffic (PASS) has a positive impact on departure frequency. The coefficient of 0.91 is in line with the 0.75 reported in previous work indicating that when capacity or aircraft size is held constant, an increase in demand is accommodated partly by higher load factors and partly by more departures (Rietveld et al., 2002). In the long term, however, when a combination of more departures and higher load factors could no longer accommodate passenger traffic levels airlines switch to larger aircraft (Graham et al., 1983). The inelastic coefficient of the passenger traffic or demand variable indicates that Philippine carriers serving 
the domestic market have the propensity to switch to larger aircraft and operate them at higher load factors as demand increases rather than add more flights proportionately. This may be due to their inability to secure additional landing slots in major airports.

The load factor (LOAD) variable behaves as expected - operating flights at higher load factors results in fewer departures or roundtrip flights. The magnitude of the decrease in the number of departures as load factor increases suggests that airlines have switched to larger aircraft in recent years. The sign of the lagged effect of the 1997 Asian financial crisis indicates that airlines reduced capacity in the form of fewer departures in response to deteriorating economic conditions.

Table 2: Estimation Results of the Passenger Equation

\begin{tabular}{|c|c|c|c|c|c|}
\hline Variable & Coefficient & Robust Standard Error & t-Statistic & \multicolumn{2}{|c|}{ Probability } \\
\hline Constant & 4.7803 & 0.3079 & 15.5274 & 0.0000 & $* * *$ \\
\hline FREQ & 1.1207 & 0.0267 & 41.9961 & 0.0000 & $* * *$ \\
\hline LOAD & 3.1183 & 0.4848 & 6.4315 & 0.0000 & $* * *$ \\
\hline \multirow[t]{4}{*}{ DIST } & 0.1090 & 0.0260 & 4.1895 & 0.0000 & $* * *$ \\
\hline & & & Adjusted $\mathrm{R}^{2}$ & 0.8968 & \\
\hline & & & Ided observations & 360 & \\
\hline & & & tem observations & 720 & \\
\hline
\end{tabular}

*** Significant at the $1 \%$ level (highly significant)

Table 2 presents the estimation results of the passenger equation. All variables are highly significant and behave as expected. Passenger traffic (PASS) increases with the number of departures (FREQ) and the elastic relationship indicates that Philippine carriers have shifted to larger aircraft and have been operating these aircraft at higher load factors in recent years. The sign of the load factor variable (LOAD) indicates that passenger traffic increases with higher load factor while its highly elastic coefficient suggests that airlines have shifted to larger aircraft and are operating these aircraft at higher load factors. The sign of the distance (DIST) variable indicates that airlines use larger aircraft in longer haul markets, which is consistent with the observation of Graham et al. (1983) in the deregulated US domestic airline industry. The use of larger aircraft in longer haul markets is consistent with passenger preferences since larger aircraft are perceived to be safer, more comfortable, and have more amenities compared with smaller aircraft (Jorge-Calderon, 1997).

\section{CONCLUSION AND POLICY IMPLICATION}

This paper examined the impact of entry and competition on airline departure frequency, as an indicator of the quality of service in the domestic industry, using data on 18 domestic routes for the period 1990-2009. An additional airline at the route level results in a slight decrease in the number of departures. The more than unitary demand elasticity of the frequency variable indicates that airlines have shifted to relatively larger aircraft. The sign and magnitude of the coefficient of the number of airlines variable in the frequency equation suggest that airlines have shifted to larger aircraft and are operating these aircraft at higher load factors resulting in fewer departures.

Capacity reductions in the form of fewer departures may help Philippine carriers improve their profitability or at least stem their losses during industry downturns such as the 1997 Asian financial crisis, 2001 terror attacks in the US, and the most recent global financial crisis. Fewer departures may indicate that the waiting time between flights has increased, which reduces the probability of matching the preferred departure times of passengers with scheduled airline service, suggesting a lower quality of service (Douglas and Miller III, 1974) in the Philippine domestic airline industry. The availability of more airlines to choose from at the route level, however, tends to reduce average fares (Borenstein, 1992; Dresner and Tretheway, 1992; Graham et al., 1983; Maillebiau and Hansen, 1995; Manuela Jr., 2007), which may offset the inconvenience of longer waiting times between flights. Reducing capacity in the form of fewer departures may have contributed to the higher load factors observed in recent years, improving the airlines' chances of returning to profitability. The viability of Philippine carriers in the long term cannot be overemphasized because the failure of some airlines may result in less competition and higher prices (Borenstein; Cooper, 1999; Marin, 1995) and even fewer departures. 
The airlines' use of larger aircraft to accommodate additional demand due to slot-constrained airports is an indication that the Philippines has inadequate infrastructure and investments in air transport. As demand for domestic air travel increases airports that have reached their maximum capacity in terms of passengers and aircraft movements will become even more congested, resulting in unsafe operating conditions. This may be one of the reasons the US Federal Aviation Administration and the European Union downgraded the Philippine civil aviation industry rating in 2008 and banned Philippine carriers in European markets in 2010, respectively. Although the opening of a third terminal at Manila's airport and the opening of new airports in Bacolod and Iloilo City have somewhat eased the congestion, there are other airports in the country that need to be upgraded and expanded to accommodate future passenger traffic growth. Kahn (1993) argues that the airline industry depends on the government to provide adequate infrastructure, facilities, and personnel at airports. The next version of the MediumTerm Philippine Development Plan should address this issue and the accompanying Medium-Term Philippine Investment Plan should provide adequate financial resources for the upgrading, expansion, and modernization of airport infrastructure, facilities, and equipment, especially at airports that serve as gateways to foreign tourists and business people and perhaps at other domestic airports since airport development and airline service help facilitate socioeconomic development.

\section{AUTHOR INFORMATION}

Wilfred S. Manuela Jr. is an associate professor at the Leadership and Strategy Department, John Gokongwei School of Management, Ateneo de Manila University, Quezon City, Philippines. He received his Ph.D. in Business Administration from the University of the Philippines, Diliman in 2005. Email: wmanuela@ ateneo.edu.

\section{REFERENCES}

1. Bailey, E. E. (1992). Airline deregulation: Confronting the paradoxes. Available at http://www.cato.org/pubs/regulation/regv15n3/reg15n3-bailey.html; accessed on October 10, 2010.

2. Baltagi, B. H. (2001). Econometric Analysis of Panel Data, second ed. West Sussex, England: John Wiley \& Sons, Ltd.

3. Besanko, D., Dranove, D., Shanley, M., and Schaefer, S. (2007). Economics of Strategy, fourth ed. Hoboken, NJ: John Wiley \& Sons, Inc.

4. Borenstein, S. (1992). The evolution of US airline competition. Journal of Economic Perspectives, 6(2), 45-73.

5. Bresnahan, T. F. and Reiss, P. C. (1991). Entry and competition in concentrated markets. Journal of Political Economy, 99(5), 977-1009.

6. Civil Aeronautics Board, Pasay City, Philippines. Airline-related data and information from 1990-2009.

7. Cooper, M. N. (1999). Freeing public policy from the deregulation debate: The airline industry comes of age. Forum on Air and Space Law: The Year in Aviation, presented at the American Bar Association on January 22, 1999. Available at http://www.consumerfed.org/pdfs/abaair1.pdf, accessed on February 23, 2011.

8. Douglas, G. W. and Miller III, J. C. (1974). Quality competition, industry equilibrium, and efficiency in the price-constrained airline market. American Economic Review, 64(4), 657-669.

9. Dresner, M. and Tretheway, M. W. (1992). Modeling and testing the effect of market structure on price: The case of international air transport. Journal of Transport Economics and Policy, 26(2), 171-184.

10. Graham, DR. R., Kaplan, D. P., and Sibley, D. S. (1983). Efficiency and competition in the airline industry. Bell Journal of Economics and Management Science, 118-138.

11. Green, W. H. (1997). Econometric Analysis, third ed. Upper Saddle River, NJ: Prentice Hall International.

12. Intriligator, M. D. (1996). Econometric Models, Techniques, and Applications, second ed. Upper Saddle River, NJ: Prentice Hall.

13. Johnston, J. and DiNardo, J. (1997). Econometric Methods, fourth ed. New York: McGraw-Hill.

14. Jorge-Calderon, J. D. (1997). A demand model for scheduled airline services on international European routes, Journal of Air Transport Management, 3(1), 23-35.

15. Kahn, A. E. (1993). Airline Deregulation. Available at http://www.econlib.org/library/Enc1/AirlineDeregulation.html, accessed on October 10, 2010. 
16. Maillebiau, E. and Hansen, M. (1995). Demand and consumer welfare impacts of international airline liberalization: The case of the North Atlantic. Journal of Transport Economics and Policy, 29(2), 115-136.

17. Manuela Jr., W. S. (2007). Airline liberalization effects on fare: The case of the Philippines. Journal of Business Research, 60(2), 161-167.

18. Marin, P. L. (1995). Competition in European Aviation: Pricing policy and market structure. Journal of Industrial Economics, 43(2), 141-159.

19. National Economic and Development Authority (2004-2010). Medium-Term Philippine Development Plan. Pasig City, Philippines. Available at http://www.neda.gov.ph/ads/mtpdp/MTPDP20042010/PDF/MTPDP2004-2010.html, accessed on February 23, 2011.

20. National Statistical Coordination Board (2010 and earlier editions). Philippine Statistical Yearbook. Makati City, Philippines.

21. Rietveld, P., Schipper, Y., and Nijkamp, P. (2002). Estimating welfare effects of European airline liberalization. WCTR Paper No. 1354, Department of Spatial and Environmental Economics, Free University, Amsterdam, the Netherlands.

22. Smith Jr., F. L. and Cox, B. (2008). Airline Deregulation. Available at http://www.econlib.org/library/Enc/AirlineDeregulation.html, accessed October 10, 2010.

23. Verbeek, M. (2000). A Guide to Modern Econometrics. West Sussex, England: John Wiley \& Sons, Ltd.

24. Wooldridge, J. M. (2002). Econometric Analysis of Cross Section and Panel Data. Cambridge, MA: MIT Press. 


\section{NOTES}

